\title{
ARMAZENAMENTO REFRIGERADO DE ABACATES 'HASS'
}

\author{
JULIANA RODRIGUES DONADON², JOSÉ FERNANDO DURIGAN ${ }^{3}$, \\ CRISTIANE MARIA ASCARI MORGADO ${ }^{4}$, LEANDRA OLIVEIRA SANTOS 5
}

RESUMO - Este trabalho objetivou determinar a ocorrência de injúria pelo frio em abacates 'Hass'. Na primeira Etapa, os abacates foram armazenados a $5^{\circ} \mathrm{C}(77 \%$ UR $), 10^{\circ} \mathrm{C}\left(79 \%\right.$ UR) e $15^{\circ} \mathrm{C}(79 \%$ UR) por até 21 dias. Aos 7; 14 e 21 dias de armazenamento, um lote com 36 frutos foi levado ao ambiente $\left(22^{\circ} \mathrm{C}\right.$ e $77 \%$ UR) para amadurecimento. Testou-se também o armazenamento a $2^{\circ} \mathrm{C}\left(74 \%\right.$ UR) e $4{ }^{\circ} \mathrm{C}(77 \%$ UR) por até 45 dias, sendo que aos 15; 30 e 45 dias, um lote com a mesma quantidade de frutos foi levado ao ambiente, mantido a $22^{\circ} \mathrm{C}$ e $77 \%$ UR. Frutos armazenados ao ambiente, desde o início, foram considerados testemunha. Avalaram-se a aparência e a luminosidade da polpa. Os frutos armazenados a $10^{\circ} \mathrm{C} \mathrm{e} 15^{\circ} \mathrm{C}$ não apresentaram sintomas de injúrias pelo frio, que foram observados nos frutos armazenados a $2^{\circ} \mathrm{C}$, por períodos superiores a 15 dias, e nos mantidos a $4^{\circ} \mathrm{C}$, por 30 dias. Quando levados ao ambiente, os frutos armazenados a $2^{\circ} \mathrm{C}$ conservaram aparência aceitável para o consumo $($ nota $=3)$ por até 10 dias, e os armazenados a $4^{\circ} \mathrm{C}$, por até 12 dias. Na segunda Etapa, analisaram-se a intensidade respiratória e a atividade das enzimas peroxidase (POD), polifenoloxidase (PPO), poligalacturonase (PG) e pectinametilesterase (PME) nos frutos armazenados a $2^{\circ} \mathrm{C}$, por 45 dias, em comparação com os testemunha. A atividade das enzimas associadas ao escurecimento, $\mathrm{POD}$ e PPO, assim como das associadas ao amaciamento da polpa, PME e PG, foi inibida pelo armazenamento a $2^{\circ} \mathrm{C}$, mas readquiriram atividade mais elevada que nos frutos-testemunha, quando foram transferidos ao ambiente, indicando estímulo devido aos danos pelo frio.

Termos para indexação : Persea americana, enzimas, armazenamento refrigerado, injúria pelo frio.

\section{COLD STORAGE OF 'HASS' AVOCADO}

ABSTRACT - This study aimed to determine the occurrence of chilling injury in 'Hass' avocado. In the first step, the avocados were stored at $5^{\circ} \mathrm{C}(77 \% \mathrm{RH}), 10^{\circ} \mathrm{C}(79 \% \mathrm{RH})$, and $15^{\circ} \mathrm{C}(79 \% \mathrm{RH})$ for up to 21 days. At 7,14 , and 21 days of storage, one lot with 36 fruits was taken to the environment $\left(22^{\circ} \mathrm{C}\right.$ and $\left.77 \% \mathrm{RH}\right)$ for maturation. Storage of fruit at $2^{\circ} \mathrm{C}(74 \% \mathrm{RH})$ and $4{ }^{\circ} \mathrm{C}(77 \% \mathrm{RH})$ for up to 45 days was also tested; at 15,30 , and 45 days, a batch of the same quantity of fruits was taken to environment and was maintained at $22^{\circ} \mathrm{C}$ and $77 \%$ RH. Fruits stored in the environment from the beginning were considered control treatment. Appearance and brightness of the pulp were evaluated. Fruits stored at $10^{\circ} \mathrm{C}$ and $15^{\circ} \mathrm{C}$ showed no symptoms of chilling injuries, however, such symptoms were observed in the fruits stored at $2^{\circ} \mathrm{C}$ for periods exceeding 15 days and in the fruits kept at $4^{\circ} \mathrm{C}$ for 30 days. Fruits stored at $2^{\circ} \mathrm{C}$, when brought to the environment, retained acceptable appearance for consumption $\left(\right.$ score $=3$ ) up to 10 days, while those ones stored at $4^{\circ} \mathrm{C}$ retained acceptable appearance for up to 12 days. In the second step, the respiratory intensity and enzymes activity of peroxidase (POD), polyphenoloxidase (PPO), polygalacturonase (PG), and pectinametilesterase (PME) in fruits stored at $2^{\circ} \mathrm{C}$ for 45 days were analyzed and compared with the control fruits. The activity of enzymes associated with browning, POD and PPO, as well as enzymes associated with the pulp softening, $\mathrm{PME}$ and $\mathrm{PG}$, was inhibited by storage at $2^{\circ} \mathrm{C}$, but regained activity higher than in control fruits, when they were transferred to the environment, indicating stimulation due to the chilling injury.

Index terms: Persea americana, enzymes, cold storage, chilling injury.

\footnotetext{
'(Trabalho 079-12). Recebido em: 31-01-2012. Aceito para publicação em: 09-08-2012.

${ }^{2}$ Eng. Agr. Dra. Bolsista Capes PNPD n ${ }^{\circ}$ 02737/09-4. Instituto Federal de Educação, Ciência e Tecnologia Goiano - IFGoiano - Campus Rio Verde - Rod. Sul Goiana Km 01, Zona Rural, Rio Verde, GO. E-mail: julianadonadon@yahoo.com.br,

${ }^{3}$ Eng. Agr. Dr. Prof. Departamento de Tecnologia - Faculdade de Ciências Agrárias e Veterinárias - FCAV/UNESP - Via de Acesso Prof. Paulo Donato Castellane s/n, Jaboticabal - SP. E-mail: jfduri@fcav.unesp.br

${ }^{4}$ Eng. Agr. Doutoranda em Agronomia. Departamento de Tecnologia - FCAV/UNESP. E-mail: critianemorgado4@yahoo.com.br ${ }^{5}$ Eng. Agr. Doutoranda em Agronomia. Departamento de Tecnologia - FCAV/UNESP. E-mail: leandraoli@hotmail.com
} 


\section{INTRODUÇÃO}

O abacate é uma fruta de grande importância mundial e tem sido produzido em quase todas as regiões tropicais e subtropicais do mundo e tem o Brasil como um dos maiores produtores (AGRIANUAL, 2008).

A produção brasileira de abacates é quase toda voltada para abastecer o mercado interno, mas o 'Hass' é produzido visando à exportação, que tem aumentado para países da América do Sul e Europa. No Brasil, os frutos desta variedade são conhecidos como "avocados" e, por serem diferenciados, são mais valorizados e com consumo em crescimento (CAMARGO; MANCO, 2008).

Para que os frutos dessa variedade alcancem mercados mais distantes e cheguem ao destino com qualidade, o desenvolvimento de tecnologia cada vez mais adequada para sua conservação se faz necessário.

A conservação sob baixa temperatura tem sido o método mais empregado, cujas condições variam de cultivar para cultivar. Abacates 'Quintal' podem ser armazenados a $7^{\circ} \mathrm{C}$ por 14 dias (GAYET et al., 1995), enquanto os 'Hass', a $2^{\circ} \mathrm{C}$ ou $5^{\circ} \mathrm{C}$, por até 4 semanas (ZAUBERMAN; JOBIN-DECOR, 1995) e os Clone II, a $4^{\circ} \mathrm{C}$ ou $0^{\circ} \mathrm{C}$, não podem ser armazenados por períodos superiores a 2 semanas (VIEIRA, 1985). As injúrias pelo frio, ou "chilling injury", são resultantes da interação entre tempos mais longos e temperaturas mais baixas no armazenamento dos frutos. Injúrias em abacates 'Pinkerton', armazenados a $2^{\circ} \mathrm{C}, 5,5^{\circ} \mathrm{C}$ e $8^{\circ} \mathrm{C}$, e em 'Fuerte', armazenados a $2^{\circ} \mathrm{C}$, foram relatadas por Bower et al. (2003).

Este trabalho teve por objetivo determinar a ocorrência de injúrias pelo frio em abacates 'Hass', armazenados em diferentes condições de tempo e temperatura, assim como avaliar a influência deste distúrbio em parâmetros bioquímicos desta fruta.

\section{MATERIAL E MÉTODOS}

Na primeira etapa, utilizaram-se abacates 'Hass', colhidos em 24-09-2007, em propriedade agrícola localizada no município de Bauru-SP (latitude $22^{\circ} 18^{\prime} 52^{\prime \prime}$ e longitude $49^{\circ} 03^{\prime} 38^{\prime \prime}$ ), a $150 \mathrm{~km}$ do Laboratório de Tecnologia dos Produtos Agrícolas da FCAV/UNESP. Os frutos, depois de cuidadosamente transportados, foram novamente selecionados quanto ao tamanho e uniformidade e, em seguida, foram lavados com água corrente e resfriados por imersão em água fria a $12^{\circ} \mathrm{C}$, para a retirada do calor de campo. $\mathrm{O}$ armazenamento foi feito a $5 \pm 1{ }^{\circ} \mathrm{C}(77 \pm 5 \%$ UR $), 10 \pm 1^{\circ} \mathrm{C}\left(79 \pm 5^{\circ} \mathrm{C}\right)$ e
$15 \pm 1^{\circ} \mathrm{C}(79 \pm 5 \%$ UR) por até 21 dias. Após $7 ; 14$ e 21 dias de armazenamento, um lote com 36 frutos, de cada temperatura, foi transferido para condição ambiente a $22 \pm 1^{\circ} \mathrm{C}$ e $77 \%$ UR. Estes frutos foram comparados com frutos-testemunha, armazenados a $22^{\circ} \mathrm{C}$ e $77 \% \mathrm{UR}$, após o resfriamento em água fria a $12^{\circ} \mathrm{C}$.

A evolução da aparência destes frutos, assim como a luminosidade da polpa foram avaliadas a cada dois dias, durante o armazenamento refrigerado e depois de transferidos para a condição de ambiente. A aparência foi sempre determinada em um lote com 10 frutos, de cada combinação tempo/temperatura, enquanto a luminosidade da polpa foi determinada em amostras tomadas em triplicata e ao acaso.

A aparência foi avaliada, utilizando-se de uma escala de pontos, em que : 5=ótima (casca sem manchas e coloração típica); 4=boa (casca com até $5 \%$ de manchas e coloração típica); $3=$ regular (casca com 6-20\% de manchas); $2=$ ruim (casca com $21-40 \%$ de manchas), e 1=péssima (casca com mais de $40 \%$ de manchas), considerando os frutos aptos para o consumo quando apresentavam nota $\geq 3$. A luminosidade da polpa foi determinada, utilizandose de reflectômetro Minolta Croma Meter CR-200b (MCGUIRE, 1992). Essas avaliações permitem determinar a vida útil dos frutos nas diferentes condições e períodos de armazenamento.

Como os abacates 'Hass' se mostraram resistentes a essas condições de refrigeração, testouse, ainda nesta etapa, em abacates colhidos em 12$08-2008$, o armazenamento a $2 \pm 1^{\circ} \mathrm{C}(74 \pm 5 \%$ UR $)$ e $4 \pm 1^{\circ} \mathrm{C}(77 \pm 5 \% \mathrm{UR})$, por 45 dias. A cada intervalo de 15 dias, um lote de cada temperatura, com 46 frutos, foi levado para a condição ambiente. Estes frutos também foram avaliados quanto à aparência e luminosidade da polpa, a cada 15 dias, durante o período sob refrigeração, e a cada dois dias, depois que eles foram transferidos para a condição ambiente. Os frutos-testemunha, mantidos em condição ambiente $\left(22 \pm 1^{\circ} \mathrm{C}, 77 \pm 5 \%\right.$ UR), também foram avaliados a cada dois dias.

$\mathrm{Na}$ segunda etapa, em $01^{\circ}-08-2009$, os abacates foram lavados, resfriados e armazenados a $2 \pm 1{ }^{\circ} \mathrm{C}(74 \% \mathrm{UR})$,por 45 dias, que foi a condição promotora de injúria indicada na primeira etapa, objetivando-se avaliar seu efeito na intensidade respiratória e na atividade das enzimas peroxidase (POD - EC. 1.11.1.7), polifenoloxidase (PPO - EC 1.10.3.1), poligalacturonase (PG - EC. 3.2.1.15) e pectinametilesterase (PME -EC3.1.1.11), em comparação com os frutos-testemunha. Amostras com cinco frutos foram tomadas, em triplicata e ao acaso, a cada 15 dias, durante o armazenamento 
refrigerado, e a cada dois dias, sob a condição ambiente $\left(22^{\circ} \mathrm{C}, 77 \% \mathrm{UR}\right)$.

A atividade respiratória foi determinada, em duplicata, utilizando-se de amostras com 10 frutos cada, que foram mantidas em recipiente, com volume conhecido, e hermeticamente fechado, por 1 hora. A porcentagem de $\mathrm{CO}_{2}$ liberada foi medida antes e depois desse tempo, nos quais se determinava o teor de $\mathrm{CO}_{2}$ em Cromatógrado CG Finnigan 9001. A quantidade de $\mathrm{CO}_{2}$ produzida no período permitiu calcular a intensidade respiratória, que foi expressa em $\mathrm{mL} \mathrm{CO}_{2} \mathrm{~kg}^{-1} \mathrm{~h}^{-1}$ (SANCHES, 2006).

A atividade das enzimas POD e PPO foi determinada no extrato de amostras homogeneizadas em tampão fosfato de potássio a $0,2 \mathrm{M}, \mathrm{pH} 6,7$, que foram centrifugadas a $1.1655 . \mathrm{g}$, por $10 \mathrm{~min}$, a $4^{\circ} \mathrm{C}$. A atividade da POD foi determinada pelo método indicado por Lima et al. (1999), tendo-se $\mathrm{H}_{2} \mathrm{O}_{2}$ como substrato e com leitura a $505 \mathrm{~nm}$, enquanto para a PPO utilizou-se fenol como substrato e leitura a 420 nm (TEIXEIRA et al., 2007). A atividade da POD foi expressa em $\mu$ mol de $\mathrm{H}_{2} \mathrm{O}_{2}$ degradado $\mathrm{g}^{-1} \mathrm{~min}^{-1}$ e a da PPO, em $\mu$ mol de fenol degradado $\mathrm{g}^{-1} \mathrm{~min}^{-1}$.

A atividade da $\mathrm{PG}$ foi determinada em extrato de polpa homogeneizada em tampão acetato de sódio a $0,1 \mathrm{M}$ (pH 6,0), contendo 1,0\% de polivinilpirrolidona e $0,5 \mathrm{M}$ de $\mathrm{NaCl}$, antes de ser filtrado e centrifugado a $2.6224 . \mathrm{g}, \mathrm{a} 4^{\circ} \mathrm{C}$. A atividade foi determinada com reação de 3,0 mL deste extrato, com 3,0 $\mathrm{mL}$ de ácido poligalacturônico a 1\%, em tampão acetato de sódio, com incubação em banho-maria a $37^{\circ} \mathrm{C}$, por 3 horas, e paralisação da reação por imersão dos tubos em água fervendo, por 5 minutos (GHAZALI; LEONG, 1987). A atividade da PG foi determinada, tendo-se o conteúdo de açúcares redutores liberados, que foi doseado pelo método de Miller (1959) e foi expressa em unidade de atividade enzimática por grama (UAE. $\mathrm{g}^{-1}$ ), definida como a quantidade de enzima capaz de produzir $1 \mu \mathrm{mol}$ de grupos redutores por grama de amostra, em 3 horas.

A atividade da pectinametilesterase (PME) foi determinada pelo método proposto por Hultin et al. (1966) e expressa em U (unidade) $\mathrm{g}^{-1} \mathrm{~min}^{-1}$. Uma unidade de PME é definida como a quantidade de enzima capaz de catalisar a desmetilação de pectina correspondente ao consumo de $1 \mathrm{nmol}$ de $\mathrm{NaOH} \mathrm{g}{ }^{-1}$ $\min ^{-1}$ de polpa.

Os resultados obtidos foram analisados, utilizando-se de regressão polinomial.

\section{RESULTADOS E DISCUSSÃO}

Os abacates armazenados a $5^{\circ} \mathrm{C}$ apresentaram ótima aparência (nota $=5$ ) durante os primeiros oito dias de armazenamento, quando ela evoluiu para boa $($ nota $=4)$ e permaneceu nessa condição até $\mathrm{o} 21^{\circ}$ dia. Quando levados ao ambiente, independentemente do período, mantiveram aparência aceitável para o consumo, nota $\geq 3$, durante seis dias. Os frutos armazenados a $10^{\circ} \mathrm{C}$ mantiveram aparência ótima por seis dias, enquanto aqueles a $15^{\circ} \mathrm{C}$, por apenas quatro dias. Nestas condições, a aparência dos frutos manteve-se aceitável para o consumo, durante 21 e 16 dias, quando armazenados a $10^{\circ} \mathrm{C}$ e $15^{\circ} \mathrm{C}$, respectivamente. Quando levados ao ambiente, os frutos armazenados $10^{\circ} \mathrm{C}$, por sete dias, mantiveram-se aceitáveis durante seis dias, e os armazenados por 14 ou 21 dias, por dois dias. Os armazenados a $15^{\circ} \mathrm{C}$, por sete e 14 dias, mantiveramse aceitáveis durante seis e dois dias, respectivamente (Tabela 1). A evolução na aparência destes frutos, independentemente da temperatura e do período de armazenamento, não foi atribuída a sintomas de injúrias por frio, mas ao amadurecimento e à senescência. Ausência de sintomas de injúrias pelo frio também foi relatada por Bower et al. (2003), em abacates 'Pinkerton', armazenados a $2^{\circ} \mathrm{C}, 5,5^{\circ} \mathrm{C}$ e $8^{\circ} \mathrm{C}$ e 'Fuerte' a $2^{\circ} \mathrm{C}$, e em 'Hass', a $5^{\circ} \mathrm{C}$, por quatro semanas (ZAUBERMAN e JOBIN-DECOR,1995; BOWER et al., 2003).

A luminosidade da polpa dos frutos armazenados a $5^{\circ} \mathrm{C}$ e a $10^{\circ} \mathrm{C}$ manteve-se em $82,76 \mathrm{e}$ 80,88 , respectivamente, enquanto a $15^{\circ} \mathrm{C}$ reduziu-se linearmente de 82,75 para 76,50, em 21 dias (Figura 1A), reafirmando o relatado por Morgado (2007). Após a transferência destes frutos para a condição ambiente, a luminosidade da polpa dos armazenados a $5^{\circ} \mathrm{C}$ manteve-se estável $(80,58-81,55)$, assim como nos armazenados a $10^{\circ} \mathrm{C}$ por 21 dias $(76,45)$ e nos testemunha $(79,15)$, que já se apresentavam maduros. Nos armazenados a $10^{\circ} \mathrm{C}$ ou $15^{\circ} \mathrm{C}$, por 7 ou 14 dias, observou-se escurecimento da polpa devido à evolução do amadurecimento (Figura 1B). Sharon e Kahn (1979) também detectaram escurecimento da polpa de abacates mantidos a $17^{\circ} \mathrm{C}$, depois de armazenados a $5^{\circ} \mathrm{C}$ por 13 dias, em relação aos frutos amadurecidos a $17^{\circ} \mathrm{C}$ (testemunha).

A vida útil dos frutos, considerando o período que permaneceram sob refrigeração e na condição ambiente, foi de 13; 20 e 27 dias, quando armazenados a $5^{\circ} \mathrm{C}$ por $7 ; 14$ e 21 dias, respectivamente, enquanto os armazenados a $10^{\circ} \mathrm{C}$ ou $15^{\circ} \mathrm{C}$, por 7 e 14 dias, apresentaram vida útil de 13 e 16 dias, respectivamente, e os armazenados a 
$10^{\circ} \mathrm{C}$ por 21 dias, vida útil de 23 dias. A vida útil dos armazenados a $15^{\circ} \mathrm{C}$ limitou-se aos 21 dias de armazenamento sob esta temperatura, e os frutostestemunha $\left(22^{\circ} \mathrm{C}\right)$ apresentaram vida útil de 14 dias.

Quando os frutos foram armazenados a $4^{\circ} \mathrm{C}$, a aparência manteve-se ótima ou boa ao longo dos 45 dias de armazenamento. Quando levados ao ambiente $\left(22^{\circ} \mathrm{C}, 77 \% \mathrm{UR}\right)$, após 15 dias de armazenamento a $4^{\circ} \mathrm{C}$, a aparência manteve- se aceitável (nota $\geq 3$ ) por mais 12 dias, mas quando levados ao ambiente depois de 30 ou 45 dias, ela se manteve aceitável por mais 10 e 8 dias, respectivamente (Tabela 2). Nos frutos armazenados a $2^{\circ} \mathrm{C}$, a aparência tornou-se regular em 15 dias, e manteve- se nessa condição por até 30 dias. Quando estes frutos foram levados ao ambiente, a aparência dos previamente armazenados por $15 \mathrm{e}$ 30 dias manteve- se aceitável (nota $\geq 3$ ) por mais 10 dias. A aparência dos frutos-testemunha manteve-se aceitável durante 22 dias (Tabela 2).

$\mathrm{O}$ escurecimento observado nos frutos durante o período de armazenamento a $2^{\circ} \mathrm{C}$ e $4^{\circ} \mathrm{C}$ foi atribuído a injúrias pelo frio (CHITARRA; CHITARRA, 2005) e manifestaram- se com manchas inicialmente amarronzadas, que se tornaram escurecidas e coalesceram. Nos abacates armazenados a $4^{\circ} \mathrm{C}$, essas manchas apareceram com tamanho menor e com menor intensidade no escurecimento e coalescimento. Sharon e Kahn (1979) também detectaram escurecimento da polpa de abacates mantidos a $17^{\circ} \mathrm{C}$, depois de armazenados a $2^{\circ} \mathrm{C}$ por 14 dias, em relação aos frutos amadurecidos a $17^{\circ} \mathrm{C}$ (testemunha).

A luminosidade da polpa dos frutos armazenados a $4^{\circ} \mathrm{C}$ manteve-se inalterada durante os 45 dias de armazenamento $(82,74)$, enquanto a dos armazenados a $2^{\circ} \mathrm{C}$ se manteve em 82,20 por até 30 dias, quando se reduziu para 74,88 (Figura 2A). Quando levados ao ambiente, esta luminosidade nos armazenados a $2^{\circ} \mathrm{C}$ reduziu-se rapidamente, de $\mathrm{L}=79,58$ para $\mathrm{L}=61,92$, o que também ocorreu nos armazenados a $4^{\circ} \mathrm{C}$ por 30 ou 45 dias, reafirmando a injúria pelo frio. Nos frutos mantidos ao ambiente (testemunha), esse escurecimento aconteceu a partir do $8^{\circ}$ dia e foi atribuído ao amadurecimento (Figura 2B). Escurecimento semelhante também foi detectado por Sharon e Kahn (1979), Zauberman et al. (1985) e Morgado (2007), e tem sido atribuído à oxidação enzimática de fenóis (CHITARRA;CHITARRA, 2005). Segundo Seymour e Tucker (1993) e Honório e Moretti (2002), as enzimas que atuam sobre os compostos fenólicos e que são liberadas do vacúolo, por ocasião da injúria, são as polifenoloxidases e as peroxidases.

A vida útil dos frutos, considerando-se o período que permaneceram sob refrigeração e na condição ambiente, foi de 23 dias para os armazenados a $2{ }^{\circ} \mathrm{C}$ por 15 dias, enquanto a dos armazenados por 30 dias, foi de 39 dias. $\mathrm{O}$ armazenamento por 45 dias prejudicou a aparência dos frutos, tornando-os inaceitáveis quando levados ao ambiente. Nos frutos armazenados a $4^{\circ} \mathrm{C}$, por $15 ; 30$ ou 45 dias, ela foi de 29; 42 e 53 dias, respectivamente.

Nos frutos do tratamento-testemunha $\left(22^{\circ} \mathrm{C}\right)$, a atividade respiratória inicial $(61,95 \mathrm{~mL} \mathrm{CO} \mathrm{kg}$ ${ }^{1} \mathrm{~h}^{-1}$ ) atingiu $114,65 \mathrm{~mL} \mathrm{CO} \mathrm{kg}^{-1} \mathrm{~h}^{-1}$ em 5 dias, para depois diminuir para $76,78 \mathrm{mLCO}_{2} \mathrm{~kg}^{-1} \mathrm{~h}^{-1}$ (Figura 3B), indicando a presença do pico climatérico. A atividade respiratória inicial dos frutos armazenados a $2^{\circ} \mathrm{C}$ reduziu-se de $61,95 \mathrm{~mL} \mathrm{CO} \mathrm{kg}^{-1} \mathrm{~h}^{-1}$ para 3,77 $\mathrm{mLCO} \mathrm{kg}^{-1} \mathrm{~h}^{-1}$, em 3 dias, e manteve-se praticamente inalterada $\left(5,45 \mathrm{~mL} \mathrm{CO}_{2} \mathrm{~kg}^{-1} \mathrm{~h}^{-1}\right)$, como resultado do resfriamento (Figura 3A). Quando eles foram levados ao ambiente, ela aumentou, atingindo seu máximo em 3 dias $\left(105,62 \mathrm{~mL} \mathrm{CO}_{2} \mathrm{~kg}^{-1} \mathrm{~h}^{-1}\right)$, para então decrescer a $96,70 \mathrm{~mL} \mathrm{CO}_{2} \mathrm{~kg}^{-1} \mathrm{~h}^{-1}$, não indicando prejuízo às suas atividades metabólicas.

Nos frutos-testemunha, a atividade da POD aumentou linearmente durante o armazenamento, de $0,652 \mu$ moles de $\mathrm{H}_{2} \mathrm{O}_{2}$ degradada $\mathrm{g}^{-1} \mathrm{~min}^{-1}$ para 3,916 $\mu$ moles de $\mathrm{H}_{2} \mathrm{O}_{2}$ degradada $\mathrm{g}^{-1} \mathrm{~min}^{-1}$, em 18 dias, indicando aumento na oxidação de compostos fenólicos. Nos frutos armazenados a $2^{\circ} \mathrm{C}$, ela se manteve inalterada, $0,942 \mu$ moles de $\mathrm{H}_{2} \mathrm{O}_{2}$ degradada $\mathrm{g}^{-1} \min ^{-1}$, que aumentou para 2,724 $\mu$ moles de $\mathrm{H}_{2} \mathrm{O}_{2}$ degradada $\mathrm{g}^{-1} \mathrm{~min}^{-1}$, em 9 dias, quando eles foram levados ao ambiente, para depois apresentar pequena redução, indicando que a atividade oxidante desta enzima também foi estimulada pela injúria pelo frio (Figura 4A). Zauberman et al. (1985) não detectaram variação na atividade da POD em abacates 'Fuerte' armazenados a $0^{\circ} \mathrm{C}, 2^{\circ} \mathrm{C}$ e $5^{\circ} \mathrm{C}$, por até 18 dias, que diminuiu quando eles foram levados ao ambiente, o que não é diferente do observado neste trabalho.

A atividade da PPO manteve-se inalterada, enquanto os frutos estiveram armazenados a $2{ }^{\circ} \mathrm{C}$ $\left(0,8710 \mu\right.$ moles de fenol degradado $\left.\mathrm{mg}^{-1} \mathrm{~min}^{-1}\right)$, que aumentou para $1,814 \mu$ moles de fenol degradado mg ${ }^{1} \mathrm{~min}^{-1}, \mathrm{em} 9$ dias, depois da transferência ao ambiente, indicando a ocorrência de escurecimento oxidativo. Nos frutos da testemunha essa atividade aumentou durante os 18 dias de armazenamento, mas com menor intensidade (Figura 4B).

A variação na atividade das enzimas POD e PPO, nas condições testadas, indica que o armazenamento a $2{ }^{\circ} \mathrm{C}$ inibiu a atividade das mesmas. Elas readquiriram atividade muito alta quando os 
frutos foram transferidos ao ambiente, indicando o estímulo causado pela condição injuriante.

A atividade da PG manteve-se inalterada enquanto os frutos estiveram armazenados a $2{ }^{\circ} \mathrm{C}$ $\left(80,74 \mathrm{UAEg}^{-1}\right)$, mas aumentou para 493,64 UAEg${ }^{1}$, em 12 dias, após a transferência para a condição ambiente. Aumento também ocorreu nos frutos da Testemunha, que foi constante até o $12^{\circ}$ dia, 618,89 $\mathrm{UAEg}^{-1}$ (Figura $5 \mathrm{~A}$ ), indicando o amaciamento dos mesmos. Atividade semelhante também foi relatada por Zauberman e Jobin-Decor (1995) e Sanches (2006).

A atividade da PME diminuiu durante os 45 dias de armazenamento a $2^{\circ} \mathrm{C}$, de $3.653,45 \mathrm{Ug}^{-}$ ${ }^{1} \mathrm{~min}^{-1}$ para $1.298,91 \mathrm{Ug}^{-1} \mathrm{~min}^{-1}(\mathrm{Y} 1=-47,41 \mathrm{x}+$ $\left.3.348,70 ; \mathrm{R}^{2}=0,86^{* *}\right)$, mas quando eles foram transferidos para a condição de ambiente, ela aumentou significativamente a partir do $6^{\circ}$ dia, a até $5.173,77 \mathrm{Ug}^{-1} \mathrm{~min}^{-1}$ (Figura $5 \mathrm{~B}$ ), como o relatado por Zauberman e Jobin-Decor (1995) em abacates 'Hass', armazenados ao ambiente, depois de mantidos a $2^{\circ} \mathrm{C}, 5^{\circ} \mathrm{C}$ e $8^{\circ} \mathrm{C}$ por 4 semanas. Nos frutos da testemunha, esta atividade reduziu-se, de $3.312,31 \mathrm{Ug}^{-1} \mathrm{~min}^{-1}$ para $1.426,86 \mathrm{Ug}^{-1} \mathrm{~min}^{-1}$ (Figura 5B), conforme o observado por Sanches (2006) em abacates 'Hass', 'Geada' e 'Quintal', amadurecidos ao ambiente. As Figuras 5A e 5B indicam que o armazenamento a $2^{\circ} \mathrm{C}$ estabilizou a atividade da PG e reduziu a da PME, indicando retardo ao amadurecimento dos frutos mantidos nessa condição.

TABELA 1- Aparência* de abacates 'Hass' armazenados a $5^{\circ} \mathrm{C}, 10^{\circ} \mathrm{C}$ e $15^{\circ} \mathrm{C}$ por até 21 dias, e depois de levados ao ambiente, assim como em frutos armazenados ao ambiente $\left(22^{\circ} \mathrm{C}, 77 \% \mathrm{UR}\right)$, ou testemunha

\begin{tabular}{|c|c|c|c|c|c|c|c|c|c|c|}
\hline \multirow{2}{*}{$\begin{array}{c}\text { Tempo } \\
\text { (dia) }\end{array}$} & \multicolumn{3}{|c|}{$5^{\circ} \mathrm{C}(77 \%$ UR $)$} & \multicolumn{3}{|c|}{$10^{\circ} \mathrm{C}(79 \%$ UR $)$} & \multicolumn{3}{|c|}{$15^{\circ} \mathrm{C}(79 \% \mathrm{UR})$} & \multirow{2}{*}{ Testemunha } \\
\hline & 7 & 14 & 21 & 7 & 14 & 21 & 7 & 14 & 21 & \\
\hline 0 & 5 & 5 & 5 & 5 & 5 & 5 & 5 & 5 & 5 & - \\
\hline 2 & 5 & 5 & 5 & 5 & 5 & 5 & 5 & 5 & 5 & - \\
\hline 4 & 5 & 5 & 5 & 5 & 5 & 5 & 5 & 5 & 5 & - \\
\hline 6 & 5 & 5 & 5 & 5 & 5 & 5 & 4 & 5 & 4 & - \\
\hline 8 & - & 5 & 5 & - & 4 & 4 & - & 3 & 3 & - \\
\hline 10 & - & 4 & 4 & - & 4 & 4 & - & 3 & 3 & - \\
\hline 12 & - & 4 & 4 & - & 3 & 4 & - & 3 & 3 & - \\
\hline 14 & - & 4 & 4 & - & 3 & 3 & - & 3 & 3 & - \\
\hline 16 & - & - & 4 & - & - & 3 & - & - & 3 & - \\
\hline 18 & - & - & 4 & - & - & 3 & - & - & 2 & - \\
\hline 21 & - & - & 4 & - & - & 3 & - & - & 2 & - \\
\hline \multicolumn{11}{|c|}{ Frutos levados ao ambiente $\left(22^{\circ} \mathrm{C}, 77 \% \mathrm{UR}\right)$} \\
\hline 0 & 5 & 4 & 4 & 5 & 3 & 3 & 4 & 3 & 2 & 5 \\
\hline 2 & 4 & 4 & 4 & 3 & 3 & 3 & 3 & 3 & 1 & 5 \\
\hline 4 & 4 & 4 & 4 & 3 & 2 & 3 & 3 & 2 & - & 5 \\
\hline 6 & 4 & 4 & 3 & 3 & 2 & 2 & 2 & 1 & - & 5 \\
\hline 8 & 2 & - & - & 2 & - & - & 2 & - & - & 4 \\
\hline 10 & - & - & - & 2 & - & - & 1 & - & - & - \\
\hline 14 & - & - & - & - & - & - & - & - & - & 3 \\
\hline 16 & - & - & - & - & - & - & - & - & - & 2 \\
\hline
\end{tabular}

*Notas para aparência: 5 = ótima; 4 = boa; $3=$ regular; $2=$ ruim, e 1 = péssima 
TABELA 2- Aparência* de abacates 'Hass' armazenados a $2^{\circ} \mathrm{C}$ e $4^{\circ} \mathrm{C}$ por até 45 dias, e depois de levados ao ambiente, assim como de frutos armazenados ao ambiente, $22^{\circ} \mathrm{C}, 77 \% \mathrm{UR}$, ou testemunha.

\begin{tabular}{|c|c|c|c|c|c|c|c|}
\hline \multirow{2}{*}{$\begin{array}{c}\text { Tempo } \\
\text { (dia) }\end{array}$} & \multicolumn{3}{|c|}{$2^{\circ} \mathrm{C}(74 \% \mathrm{UR})$} & \multicolumn{3}{|c|}{$4^{\circ} \mathrm{C}(77 \% \mathrm{UR})$} & \multirow{2}{*}{ Testemunha } \\
\hline & 15 & 30 & 45 & 15 & 30 & 45 & \\
\hline 0 & 5 & 5 & 5 & 5 & 5 & 5 & - \\
\hline 15 & 3 & 3 & 3 & 5 & 5 & 5 & - \\
\hline 30 & - & 3 & 3 & - & 5 & 5 & - \\
\hline 45 & - & - & 2 & - & - & 4 & - \\
\hline \multicolumn{8}{|c|}{ Frutos levados ao ambiente $\left(22^{\circ} \mathrm{C}, 77 \% \mathrm{UR}\right)$} \\
\hline 0 & 3 & 3 & 2 & 5 & 5 & 4 & 5 \\
\hline 2 & 3 & 3 & 2 & 4 & 4 & 3 & 5 \\
\hline 4 & 4 & 3 & 2 & 4 & 4 & 3 & 5 \\
\hline 6 & 3 & 3 & 2 & 4 & 4 & 3 & 4 \\
\hline 8 & 3 & 3 & 2 & 4 & 4 & 3 & 4 \\
\hline 10 & 3 & 3 & - & 4 & 4 & - & 4 \\
\hline 12 & 2 & 2 & - & 4 & 3 & - & 4 \\
\hline 14 & 2 & 2 & - & 3 & 2 & - & 3 \\
\hline 16 & - & - & - & - & - & - & 3 \\
\hline
\end{tabular}

*Notas para aparência: 5 = ótima; 4 = boa; 3 = regular; 2 = ruim, e 1 = péssima

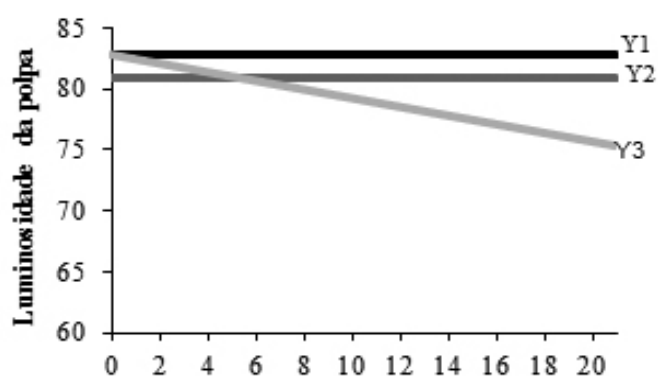

Tempo de armazenamento (dia)
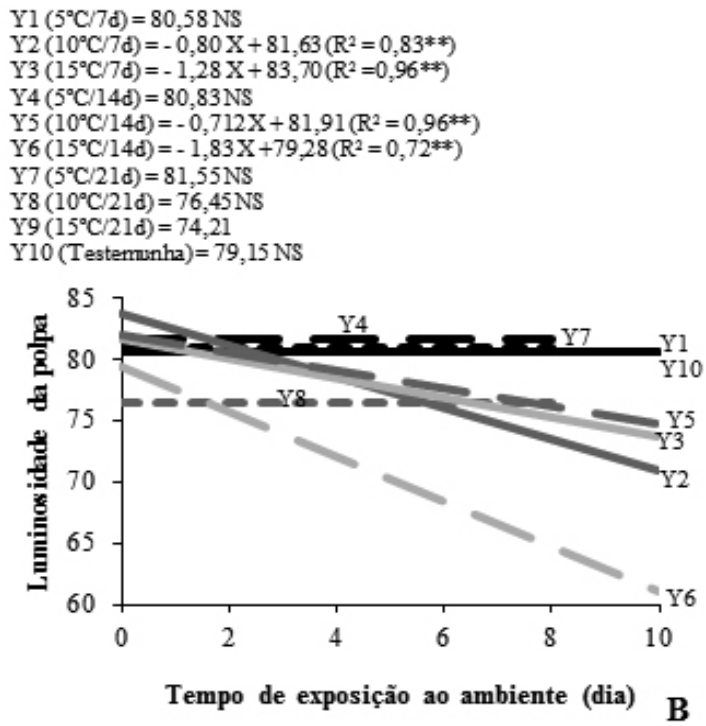

FIGURA 1- Luminosidade da polpa de abacates 'Hass' armazenados a $5^{\circ} \mathrm{C}, 10^{\circ} \mathrm{C}$ e $15^{\circ} \mathrm{C}$ por até 21 dias (A), e depois de levados ao ambiente (B), assim como de frutos armazenados ao ambiente $\left(22^{\circ} \mathrm{C}\right)$, ou testemunha. 
$\mathrm{Y} 1\left(2^{\circ} \mathrm{C}\right)=-0,0005 \mathrm{X}^{3}+0,03 \mathrm{X}^{2}-0,47 \mathrm{X}+83,22\left(\mathrm{R}^{2}=1,0^{* *}\right)$ $\mathrm{Y} 2\left(4^{\circ} \mathrm{C}\right)=82,14 \mathrm{NS}$

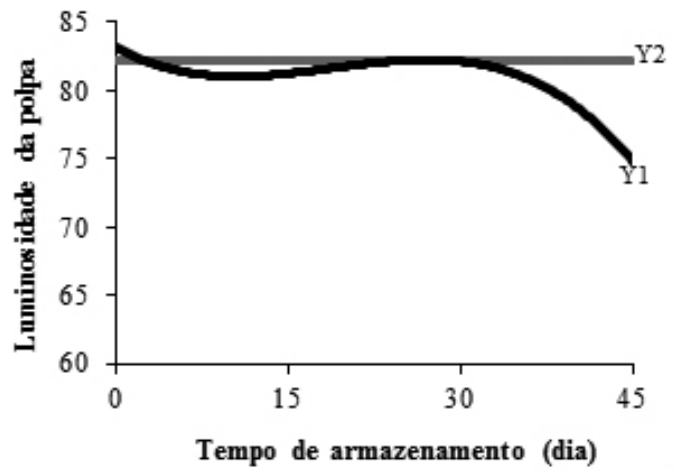

$\mathrm{Y} 1\left(2^{\circ} \mathrm{C} / 15 \mathrm{~d}\right)=-0,08 \mathrm{X}^{2}+0,07 \mathrm{X}+81,50\left(\mathrm{R}^{2}=0,9742^{* *}\right)$ $\mathrm{Y} 2\left(4^{\circ} \mathrm{C} / 15 \mathrm{~d}\right)=75,37 \mathrm{NS}$

$\mathrm{Y} 3\left(2^{\circ} \mathrm{C} / 30 \mathrm{~d}\right)=-1,36 \mathrm{X}+81,75\left(\mathrm{R}^{2}=0,87^{* *}\right)$

$\mathrm{Y} 4\left(4^{\circ} \mathrm{C} / 30 \mathrm{~d}\right)=-0,01 \mathrm{X}^{3}+0,30 \mathrm{X}^{2}-2,26 \mathrm{X}+82,99\left(\mathrm{R}^{2}=0,96^{*}\right)$

$\mathrm{Y} 5(2 / 45 \mathrm{~d})=-1,57 \mathrm{X}+75,22\left(\mathrm{R}^{2}=0,98 *\right.$

$\mathrm{Y} 6\left(4^{\circ} \mathrm{C} / 45 \mathrm{~d}\right)=-1,6707 \mathrm{X}+80,83\left(\mathrm{R}^{2}=0,95^{*}\right)$

$\mathrm{Y} 7($ Testemunha $)=-0,07 \mathrm{X}^{2}+0,75 \mathrm{X}+79,02\left(\mathrm{R}^{2}=0,91^{*}\right)$

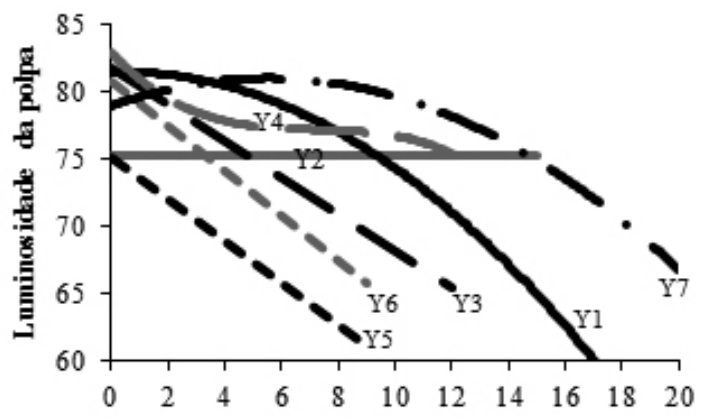

Tempo de exposição ao ambiente (dia) B

FIGURA 2- Luminosidade da polpa em abacates 'Hass' armazenados a $2^{\circ} \mathrm{C}$ e $4^{\circ} \mathrm{C}$ por até 45 dias (A), e depois de levados ao ambiente, assim como em frutos-testemunha (B).

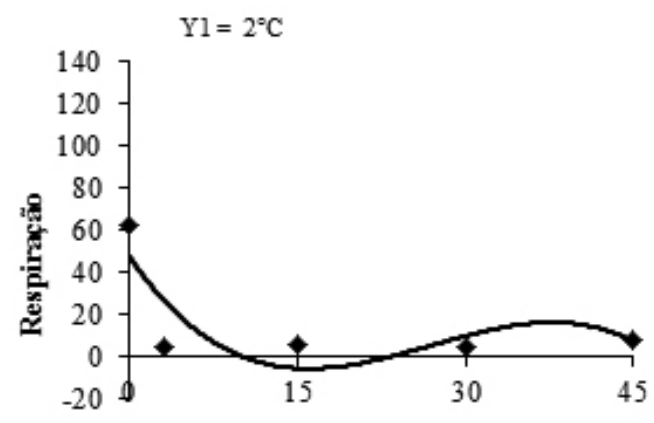

Tempo de armazenamento (dia)

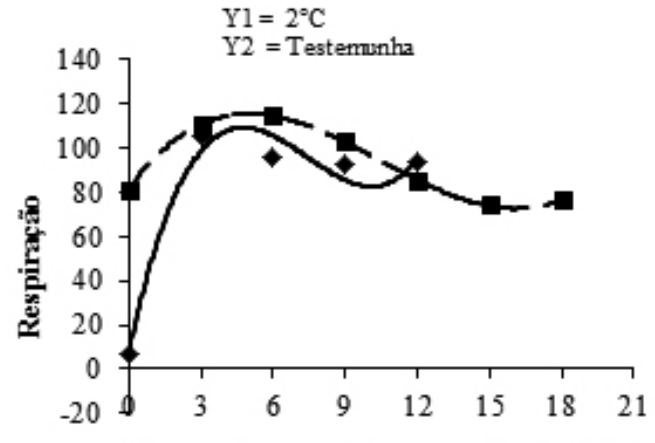

Tempo de exposição ao ambiente (dia) B

FIGURA 3- Atividade respiratória em abacates 'Hass' durante o armazenamento a $2^{\circ} \mathrm{C}$ por 45 dias (A), e depois de levados ao ambiente, e em frutos-testemunha (B).

$\mathrm{Y} 1\left(2^{\circ} \mathrm{C}\right)=-0,029 \mathrm{X}^{2}+0,47 \mathrm{X}+0,72\left(\mathrm{R}^{2}=0,82^{* *}\right)$
$\mathrm{Y} 2($ Testemunha $)=0,1920 \mathrm{x}+0,8823(\mathrm{R} 2=0,8775 * *)$

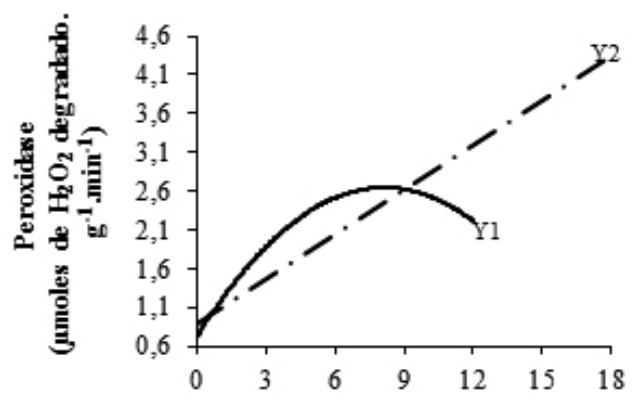

Tempo de exposição ao ambiente (dia) A
Y1 $\left(2^{\circ} \mathrm{C}\right)=-0,003 \mathrm{X}^{3}+0,05 \mathrm{X}^{2}-0,14 \mathrm{X}+1,06\left(\mathrm{R}^{2}=0,98^{*}\right)$ $\mathrm{Y} 2($ Testemunha $)=0,043 \mathrm{X}+0,89\left(\mathrm{R}^{2}=0,73 * *\right)$

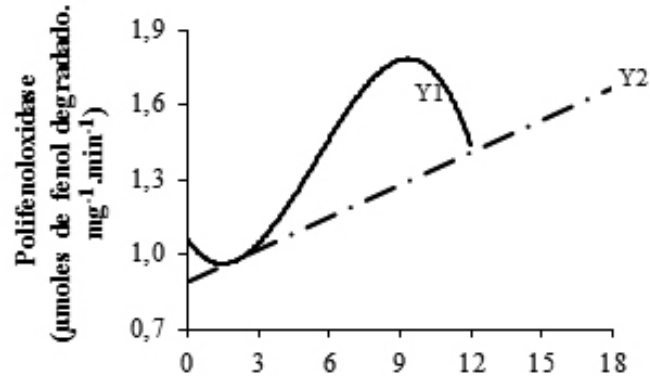

Tempo de exposição ao ambiente (dia) B

FIGURA 4 - Atividade da peroxidase (A) e da polifenoloxidase (B) em abacates 'Hass' levados ao ambiente, depois de armazenados a $2^{\circ} \mathrm{C}$ por 45 dias, e em frutos-testemunha. 
$\mathrm{Y} 1\left(2^{\circ} \mathrm{C}\right)=0,93 \mathrm{X}^{3}-23,99 \mathrm{X}^{2}+190,08 \mathrm{X}+50,15\left(\mathrm{R}^{2}=0,99 *\right)$

$\mathrm{Y} 2$ (Testemunha) $=-3,51 \mathrm{X}^{2}+92,15 \mathrm{X}+18,90\left(\mathrm{R}^{2}=0,85^{* *}\right)$

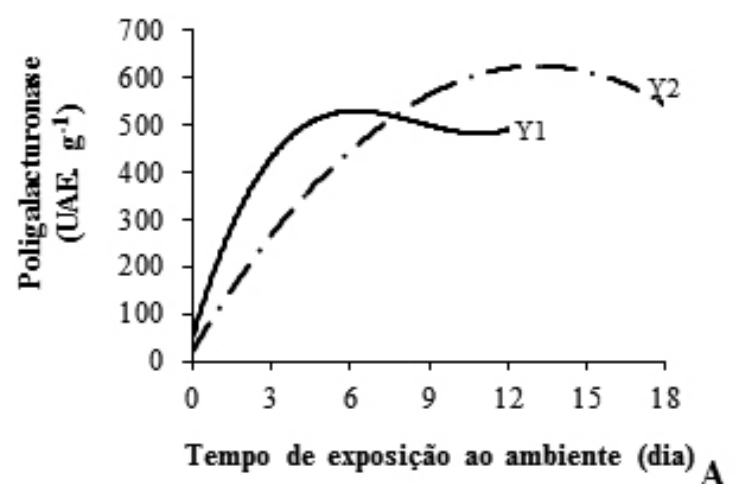

Y1 $\left(2^{\circ} \mathrm{C}\right)=17,23 \mathrm{X}^{3}-263,59 \mathrm{X}^{2}+1003,60 \mathrm{X}+1365,60\left(\mathrm{R}^{2}=0,97^{*}\right.$ $\mathrm{Y} 2($ Testemwnha $)=15,32 \mathrm{X}^{2}-355,80 \mathrm{X}+2954,60\left(\mathrm{R}^{2}=0,84^{*}\right)$

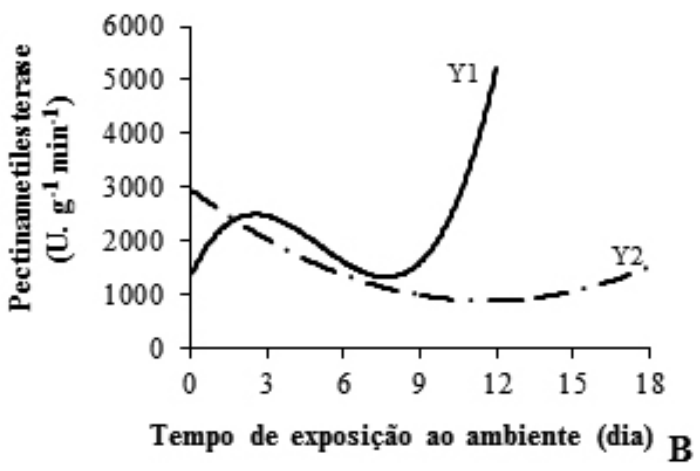

FIGURA 5-Atividade da poligalacturonase (A) e da pectinametilesterase (B) em abacates 'Hass' levados ao ambiente, depois de armazenados a $2^{\circ} \mathrm{C}$ por 45 dias, e em frutos- testemunha.

\section{CONCLUSÕES}

Abacates 'Hass' não apresentam injúrias pelo frio, quando armazenados a $5^{\circ} \mathrm{C}, 10^{\circ} \mathrm{C}$ e $15^{\circ} \mathrm{C}$ por até 21 dias. Frutos armazenados a $2^{\circ} \mathrm{C}$, por período igual ou superior a 15 dias, apresentam injúrias, assim como a $4^{\circ} \mathrm{C}$, por período igual ou superior a 30 dias.

A atividade das enzimas associadas ao escurecimento, peroxidase e polifenoloxidase, assim como das associadas ao amaciamento da polpa, pectinametilesterase e poligalacturonase, é inibida pelo armazenamento a $2^{\circ} \mathrm{C}$, mas readquiriram atividade mais elevada que nos frutos-testemunha, quando são transferidos ao ambiente, indicando estímulo devido aos danos pelo frio.

\section{AGRADECIMENTOS}

À FAPESP (Processo 05/55422-7), pelo auxílio financeiro.

\section{REFERÊNCIAS}

AGRIANUAL: anuário da agricultura brasileira. São Paulo: FNP Consultoria e Comércio, 2008. p. 143-147.

BOWER, J. P.; DENNISON, M. T.; FOWLER, K. Avocado and mango cold storage damage as related to water loss control. Acta Horticulturae, The Hague, n. 628, p. 401-406, 2003.

CAMARGO, G. F.; MANCO, J. Participação no mercado de abacate no ETSP da CEAGESP em 2002. Disponível em: $<$ http://www.todafruta.com. $\mathrm{br} /$ todafruta/mostra_conteúdo.asp? conteudo $=6276>$. Acesso em: 23 set. 2008.

CHITARRA, M. I. F.; CHITARRA, A. B. Póscolheita de frutos e hortaliças: fisiologia e manuseio. Lavras: Ed. UFLA, 2005. 785 p.

GAYET, J. P.; BLEINROTH, E. W.; MATALLO, M.; GARCIA, E. E. C.; GARCIA, A. E.; ARDITO, E. F. G.; BORDIN, M. Abacate para exportação: procedimentos de colheita e pós-colheita. Brasília: EMBRAPA, 1995. 53p. (Série de publicações técnicas da FRUPEX)

GHAZALI, H. M. N.; LEONG, N. Polygalacturonase activity in starfruit. Food Chemistry, London, v. 24, n.1, p.147-157, 1987.

HONÓRIO, S. L.; MORETTI, C. L. Fisiologia póscolheita de frutas e hortaliças. In: CORTEZ, L. A. B.; HONÓRIO, S. L.; MORETTI, C. L. Resfriamento de frutas e hortaliças. Brasília: Embrapa Hortaliças, 2002. p. 60-81.

HULTIN, H.O.; SUN, B.; BULGER, J. Pectin methyl esterase of banana. Purification and properties. Journal of Food Science, Chicago, v.31, n.3, p. 320-327, 1966.

LIMA, G.P.P.; BRASIL, O.G.; OLIVEIRA, A.M. de. Poliaminas e atividade da peroxidase em feijão (Phaseolus vulgaris L.) cultivado sob ambiente salino. Scientia Agricola, Piracicaba, v.56, n.1, p.21-26, 1999. 
McGUIRE, R.G. Reporting of objective color measurements. HortScience, Alexandria, v.27, p.254-255. 1992.

MILLER, G. L. Use of dinitrosalicylic acid reagent for determination of reducing sugars. Analytical Chemistry, Washington, v. 31, n. 3, p. 426-428. 1959.

MORGADO, C. M. A. Conservação pós-colheita de abacates 'Geada'e 'Quintal', em diferentes pontos de colheita, com o uso de diferentes temperaturas e proteções. 2007. 89f. Monografia (Trabalho de Graduação em Agronomia) - Faculdade de Ciências Agrárias e Veterinárias, Universidade Estadual Paulista, Jaboticabal, 2007.

SANCHES, J. Efeito de injurias mecânicas na qualidade pós-colheita de abacates. 2006. 125f. Tese (Doutorado em Produção Vegetal) - Faculdade de Ciências Agrárias e Veterinárias, Universidade Estadual Paulista, Jaboticabal, 2006.

SEYMOUR, G. B.; TUCKER, G. A. Avocado. In: SEYMOUR, G. B.; TAYLOR, J. E.; TUCKER, G. A. Biochemistry of fruit ripening. London: Chapman \& Hall, 1993. p. 53-76.
SHARON, O.; KAHN, V. Browning potential, $\mathrm{PPO}$, catalase and acid phosphatase activities during ripening of non-chilled and chilled avocado. Journal of Science Food and Agriculture, Chicago, v. 30, p. 634-638, 1979.

TEIXEIRA, G.H.de A.; DURIGAN, J.F.; ALVES, R.E.; O'HARE, T.J. Use of modified atmosphere to extend shelf life of fresh-cut carambola (Averhoa carambola L.). Postharvest Biology and Technology, Amsterdam, v.44, n.1, p.80-85, 2007.

VIEIRA, G. Influência da temperatura e do tempo de armazenamento na conservação do abacate (Perseaamericana Mill.). 1985. 41f. Dissertação (Mestrado em Fitotecnia) - Universidade Federal de Viçosa, Viçosa, 1985.

ZAUBERMAN, G.; JOBIN-DECOR, M. P. Avocado (Perseaamericana Mill.) quality in response to lowtemperature storage. Postharvest Biology and Technology, Amsterdam, v.5, p. 235-243, 1995.

ZAUBERMAN, G.; FUCHS, Y.; AKERMAN, M. Peroxidase activity in avocado fruit stored at chilling temperatures. Scientia Horticulturae, Amsterdam, v. 26, p. 261-265, 1985. 